\title{
CLINICAL AND HISTOPATHOLOGICAL STUDY OF CUTANEOUS TUBERCULOSIS
}

Ashok S. Hogade ${ }^{1}$, Dayanand Raikar², Nagendra Mantale ${ }^{3}$, Shrinivas Raikar ${ }^{4}$

\section{HOW TO CITE THIS ARTICLE:}

Ashok S. Hogade, Dayanand Raikar, Nagendra Mantale, Shrinivas Raikar. "Clinical and Histopathological Study of Cutaneous Tuberculosis". Journal of Evolution of Medical and Dental Sciences 2014; Vol. 3, Issue 45, September 18; Page: 11016-11020, DOI: 10.14260/jemds/2014/3437

ABSTRACT: Extrapulmonary tuberculosis constitutes about $10 \%$ of all cases of tuberculosis, and cutaneous tuberculosis makes up only a small proportion of these cases. Despite prevention programs, tuberculosis is still progressing endemically in developing countries. Commonest clinical variant of cutaneous tuberculosis in our study was tuberculous verrucosa cutis (TBVC) seen in $46.66 \%$ patients followed by Lupus vulgaris seen in $33.33 \%$ patients followed by scrofuloderma (13.33\%), papulonecrotic tuberculide (6.66\%). The commonest site of involvement was upper limbs seen in $46.66 \%$ patients followed by lower limb seen in $20 \%$ patients, face, neck, inguinal region, axilla, chest in $6.66 \%$ and generalized pappilary eruptions in $6.66 \%$ patients. Maximum percentage of patients (53.3\%) had duration of cutaneous tuberculosis between 1-3 years followed by 33.33\% between 1-6 months, 6.66\% had duration of cutaneous tuberculosis between 7-12 months, and rest $6.66 \%$ had duration between 4-6 years. The commonest histopathological feature in our study was tuberculoid granuloma with epithelioid and Langhans giant cells seen in $70 \%$ patients, hyperkeratosis was seen in $13.33 \%$ patients and AFB bacilli were seen in $6.66 \%$ patients.

KEYWORDS: Chancre, cutaneous, gumma, lupus vulgaris, scufuloderma, tuberculids, tuberculosis.

INTRODUCTION: Cutaneous tuberculosis is a form of extra pulmonary tuberculosis with varied clinical presentation determined by the route of infection as well as status of cellular immunity of the host. Most of the cases of cutaneous tuberculosis can be diagnosed clinically but some cases really pose diagnostic challenges. Histopathological features are not pathognomonic but play a corroborative role in diagnosis. ${ }^{1}$

Diagnosis of cutaneous tuberculosis (CTB) is complicated and requires a full work-up, including a detailed history and physical examination, careful consideration of clinical presentation, skin biopsy with histological analysis, and special staining methods for identification of acid-fast bacilli (AFB) and the use of other diagnostic tests, such as chest X-ray and sputum culture. ${ }^{2-4}$

This study was conducted to know the different forms of cutaneous tuberculosis and their histopathological correlation, their incidence, association with other diseases, association with other foci of tuberculosis in patients attending outpatient department of along with usefulness of common diagnostic investigations and response to commonly used drugs.

MATERIALS AND METHODS: We selected 30 patients who were clinically suspected to have cutaneous tuberculosis. To rule out tuberculosis in other organs, chest X-ray and sputum-smear examination for AFB on three consecutive days were performed for all patients. Skin biopsy was performed in all cases and examined after staining with hematoxylin and eosin. Skin biopsy, Mantoux test, chest X-ray, haemogram, and serum biochemistry were performed on these patients. 
Other tests including fine needle aspiration cytology, lymph node biopsy, and radiological imaging were conducted when clinically indicated.

RESULTS: In our study, maximum (40\%) patients were between 20-29years, 22.66\% patients were between 10-19 years, $13.33 \%$ patients were between 0-9 years, and 40-49 years each and 6.66\% patients were 60 years and above. Males outnumbered females and male to female ratio was 1.14: 1. [Table 1].Commonest clinical variant of cutaneous tuberculosis in our study was tuberculous verrucosa cutis(TBVC) [Figure 1 and 3] seen in 46.66\% patients followed by Lupus vulgaris [Figure 3] seen in $33.33 \%$ patients followed by scrofuloderma (13.33\%), papulonecrotic tuberculide (6.66\%) [Figure 3].

The commonest site of involvement was upper limbs seen in $46.66 \%$ patients followed by lower limb seen in 20\% patients, face, neck, inguinal region, axilla, chest in $6.66 \%$ and generalized papillary eruptions in $6.66 \%$ patients [Table 4]. Maximum percentage of patients (53.3\%) had duration of cutaneous tuberculosis between 1-3 years followed by 33.33\% between 1-6 months, $6.66 \%$ had duration of cutaneous tuberculosis between $7-12$ months, and rest $6.66 \%$ had duration between 4-6 years [Table 2].

The commonest histopathological feature in our study was tuberculoid granuloma with epithelioid and Langhans giant cells seen in 70\% patients, hyperkeratosis was seen in $13.33 \%$ patients and AFB bacilli were seen in $6.66 \%$ patients [Table 3 ].

\begin{tabular}{|c|c|c|c|c|c|}
\hline Sl. No. & Age-group (years) & Male & Female & Total & Percentage \\
\hline 1 & $0-9$ & 2 & 2 & 4 & $13.33 \%$ \\
\hline 2 & $10-19$ & 6 & 2 & 8 & $26.66 \%$ \\
\hline 3 & $20-29$ & 4 & 8 & 12 & $40 \%$ \\
\hline 4 & $30-39$ & 0 & 0 & 0 & $0 \%$ \\
\hline 5 & $40-49$ & 2 & 2 & 4 & $13.3 \%$ \\
\hline 6 & $50-59$ & 0 & 0 & 0 & $0 \%$ \\
\hline 7 & 60 and above & 2 & 0 & 2 & $6.66 \%$ \\
\hline \multicolumn{7}{|c|}{ Total } & $\mathbf{1 6}$ & $\mathbf{1 4}$ & $\mathbf{3 0}$ & $\mathbf{1 0 0 \%}$ \\
\hline
\end{tabular}

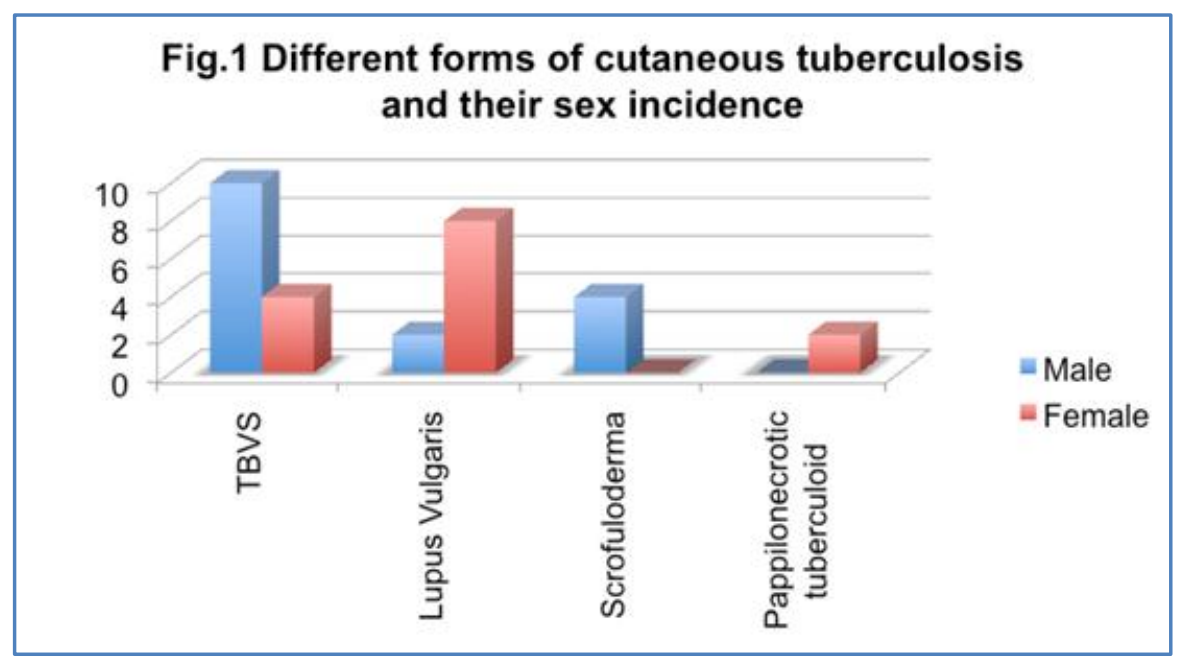




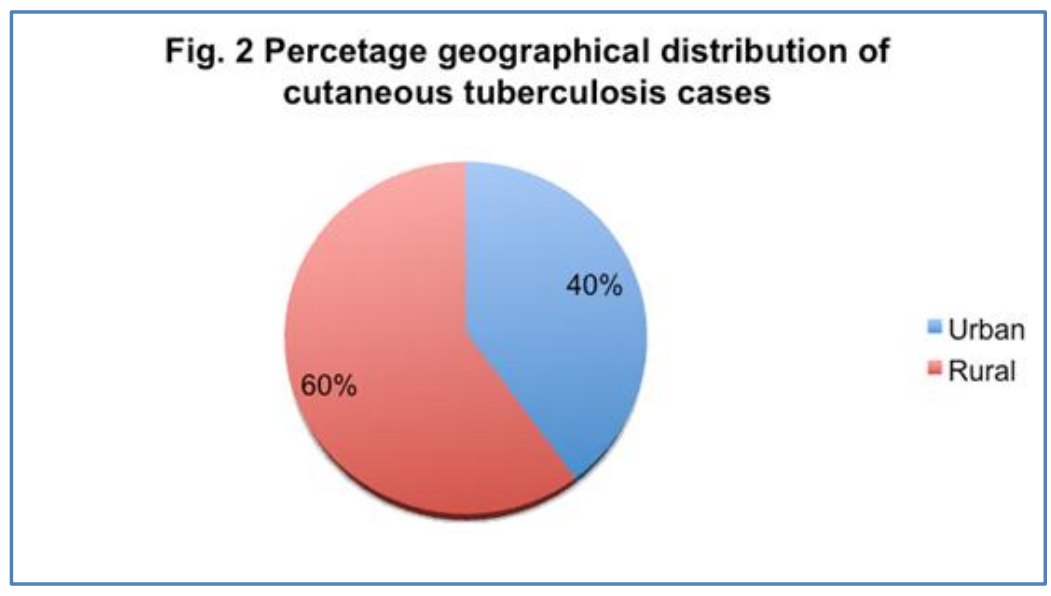

Fig. 3 Distribution of various forms of cutaneous tuberculosis

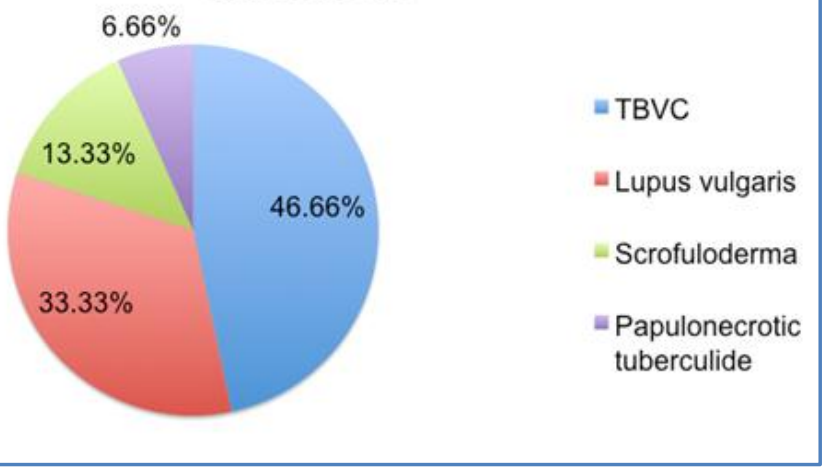

\begin{tabular}{|c|l|c|c|c|c|c|}
\hline Sl. No. & Type of cutaneous TB & $\mathbf{1 - 6}$ months & $\mathbf{7 - 1 2}$ months & $\mathbf{1 - 3}$ years & 4-6 years & Total \\
\hline 1 & TBVC & 4 & 2 & 6 & 2 & 14 \\
\hline 2 & Lupus vulgaris & 4 & - & 6 & - & 10 \\
\hline 3 & Scrofuloderma & 2 & - & 2 & - & 4 \\
\hline 4 & Papulonecrotic tuberculide & - & - & 2 & - & 2 \\
\hline Total & & $\mathbf{1 0}$ & $\mathbf{2}$ & $\mathbf{1 6}$ & $\mathbf{2}$ & $\mathbf{3 0}$ \\
\hline \multicolumn{2}{r}{} & $33.33 \%$ & $6.66 \%$ & $53.33 \%$ & $6.66 \%$ & $100 \%$ \\
\hline
\end{tabular}

Table 2: Duration wise distribution of cutaneous tuberculosis

\begin{tabular}{|c|l|c|c|c|c|c|c|}
\hline Sl. No. & \multicolumn{1}{|c|}{ Features } & TBVC & LV & Scro & PNT & Total & Percentage \\
\hline 1 & Inflammatory cells & 6 & 3 & 1 & - & 10 & $33.33 \%$ \\
\hline 2 & Epitheloid cells & 11 & 3 & 5 & 2 & 21 & $70 \%$ \\
\hline 3 & Giant cells & 9 & 4 & 4 & 4 & 21 & $70 \%$ \\
\hline 4 & Hyperkeratosis & 1 & 2 & - & 1 & 4 & $13.33 \%$ \\
\hline 5 & Tuberculoid granuloma & 10 & 5 & 4 & 2 & 21 & $70 \%$ \\
\hline 6 & AFB Table 3: Histopathological results \\
\hline
\end{tabular}




\begin{tabular}{|l|c|c|c|c|c|c|}
\hline \multicolumn{1}{|c|}{ Area of involvement } & TBVC & LV & Scro & PNT & Total & Percentage \\
\hline Upper limbs & 12 & 2 & & & 14 & $46.66 \%$ \\
\hline Lower limbs & 2 & 4 & & & 6 & $20 \%$ \\
\hline Chest & & 2 & & & 2 & $6.66 \%$ \\
\hline Inguinal area & & & 2 & & 2 & $6.66 \%$ \\
\hline Face & & 2 & & & 2 & $6.66 \%$ \\
\hline Neck and axilla & & & 2 & & 2 & $6.66 \%$ \\
\hline Generalized papillar eruptions & & & & 2 & 2 & $6.66 \%$ \\
\hline
\end{tabular}

Table 4: Percentage of distribution of lesions of cutaneous tuberculosis on body

DISCUSSION: To conclude, although the incidence of CTB is rare, it should be considered in patients presenting with atypical skin lesions suggestive of underlying infectious etiology. ${ }^{5}$ Cutaneous tuberculosis is an important health problem in this part of the country especially in lower socioeconomic group. Parents should be encouraged for routine BCG vaccination as well as proper nutrition of their children.

The laboratory diagnosis of cutaneous tuberculosis is difficult. ${ }^{6}$ Histopathological findings are characteristic but not pathognomonic and are shared by other granulomatous diseases including leprosy, sarcoidosis, leishmaniasis, and subcutaneous fungal infections.

\section{REFERENCES:}

1. Binod Kumar Thakur, Shikha Verma, Debeeka Hazarika. A Clinicopathological Study of Cutaneous Tuberculosis at Dibrugarh District, Assam. Indian J Dermatol. 2012 Jan-Feb; 57 (1): 63-65.

2. Mac Gregor RR. Cutaneous tuberculosis. Clin Dermatol. 1995; 13: 245-55. [PubMed].

3. Bhutto AM, Solangi A, Khaskhely NM. Clinical and epidemiological observations of cutaneous tuberculosis in Larkana, Pakistan. Int J Dermatol. 2002; 41:159-65. [PubMed].

4. Barbagallo J, Tager P, Ingleton R. Cutaneous tuberculosis: Diagnosis and treatment. Am J Clin Dermatol.2002; 3:319-28. [PubMed].

5. Lai-Chong JE, Perez A, Tang V. Cutaneous manifestations of tuberculosis. Clin Exp Dermatol.2007; 32: 461-6.

6. Sehgal VN, Jain MK, Srivastava GP. Changing patterns of cutaneous tuberculosis. A prospective study. Int J Dermatol. 1989; 28: 231-5. 


\section{ORIGINAL ARTICLE}

\section{AUTHORS:}

1. Ashok S. Hogade

2. Dayanand Raikar

3. Nagendra Mantale

4. Shrinivas Raikar

\section{PARTICULARS OF CONTRIBUTORS:}

1. Professor and HOD, Department of Dermatology, MRMC, Gulbarga.

2. Associate Professor, Department of Dermatology, KBN Medical College, Gulbarga.

3. Assistant Professor, Department of Dermatology, MRMC, Gulbarga.

4. Post Graduate, Department of Pharmacology, MRMC, Gulbarga.

\section{NAME ADDRESS EMAIL ID OF THE} CORRESPONDING AUTHOR:

Dr. Ashok Hogade, HOD, Department of Dermatology, M.R. Medical College, Gulbarga-585105.

Email: ahogade@yahoo.com

Date of Submission: 05/09/2014. Date of Peer Review: 06/09/2014. Date of Acceptance: 11/09/2014. Date of Publishing: 17/09/2014. 